Página inicial: 375 - Página final: 391

TIPO DE ARTÍCULO: DE REFLEXIÓN

\title{
MEMORIA E HISTORIA DESAFÍOS A LAS PRÁCTICAS POLÍTICAS DE OLVIDO EN AMÉRICA LATINA.
}

MEMORY AND HISTORY. CHALLENGES TO THE FORGOTTEN POLITICAL PRACTICES IN LATIN AMERICA.

RECIBIDO: ENERO 2015 REVISADO: ABRIL $2015 \quad$ CEPTADO: 2 DE MAYO DE 2015

Por: Estela Quintar. ${ }^{1}$

\section{RESUMEN:}

Memoria y olvido han sido, desde la emergencia de nuestra especie en este mundo, significantes que nombran el gran desafio de la supervivencia simbólica en el mundo de la vida. Es la constante lucha por registrar no sólo nuestra propia existencia sino un modo de transitarla, de construirla y vivirla, exorcizando así el fantasma del olvido; porque el olvido es el enemigo de la vida misma, es el nombre de las experiencias perdidas ¿Qué sería de nosotros si olvidáramos las experiencias - más allá de su belleza o dolor - y los aprendizajes que, muchas veces con gran esfuerzo, hemos caminado en este entrelazamiento entre la especie humana y el transcurrir del tiempo?

\section{PALABRAS CLAVE:}

Olvido, memoria, historia, identidad

\section{ABSTRACT:}

Memory and oblivion have been, since the emergence of our species in this world, signifiers that named the great challenge of symbolic survival in the world of life. It is the constant struggle to record not only our own existence, but a way to move it, build it and live it, thus exorcising the ghost of oblivion; because oblivion is the enemy of life itself, it is the name of the lost experience. What would become of us if we forget experiences - beyond their beauty or pain-and the learning that, many times with great effort, we have stepped into this entanglement between the human species and the passing of time?

\section{KEY WORDS:}

Oblivion, memory, history, and identity.

\footnotetext{
${ }^{1}$ Pedagoga y Maestra argentina, Actual Directora del Instituto de pensamiento y cultura para América Latina (Ipecal - México). México. Contacto: estelaquintar@ipecal.edu.mx
} 


\section{Introducción.}

Todos sabemos los estragos que causa enfermedades como el Alzheimer, que atacan directamente la memoria del sujeto padeciente; y, por ende su subjetividad; no es dificil entonces imaginar lo que podría ser un pueblo entero sin memoria.

Cabe entonces preguntarnos: ¿Qué nos impulsa a ir más allá del recuerdo? ¿Qué nos lleva a sabernos más allá de este transitar en el presente?; ¿Qué nos impulsa a buscar dejar marca y reconocimiento de nuestro existir en nuestros hijos y los hijos de nuestros hijos, como reza la biblia y la mayoría de las creencias religiosas? ¿Qué hace a nuestro deseo de quedar en la memoria de nuestra posteridad, de ir más allá de este confuso sentir flotante entre lo real y lo posible de ser, en una realidad configurada en sistemas de creencias, mitos, y ritos?

¿Será nuestra inocente percepción de la eternidad?, ¿será nuestro siempre amenazante temor a la finitud?

Indudablemente éstas y muchas otras preguntas que podriamos hacernos en el orden de lo existencial, en relación a nuestro propio transcurrir, adquieren otra dimensión y profundidad cuando nos las planteamos desde el reconocernos y asumirnos como habitantes de la relación con otro; cuando reconocemos que nuestro propio existir es dable porque hay un otro que lo hace posible, que refleja la inmensidad de ser siendo, que nunca es "uno" sino muchos en uno; recordándonos que, en definitiva, estamos siendo la sintesis transgeneracional de muchos otros que nos antecedieron y que resuenan en cada gota de ADN. La comunidad humana que somos adquiere sentido en la memoria; memoria que nos enlaza, fundamentalmente, con la experiencia del aprendizaje de lo humano en relación con el mundo de la vida material y cósmica.

Desde esta perspectiva, la memoria no es recuerdo, no es sólo evocación de lo experienciado; la memoria se configura en la trama de sentidos y significados que los sujetos concretos le otorgamos a las experiencias que vivimos desde el presente que transitamos.

Es por esto que la historia es movimiento, porque el sujeto que hace esta historia se configura en el constante devenir del presente, siempre complejo y cambiante. Es decir, es el sujeto en el movimiento de su pensamiento y su transcurrir quien construye la historia.

Así, tiempo resignificado, espacio vivido y el otro en relación intersubjetiva -presente o ausente- en sus narraciones, articulan el sustrato de la construcción de la memoria y de la historia. Historia entendida no como historiografia, sino como construcción intencionada de la organización de esa trama histórica que es la memoria y que configura identidad y formas de transmitir-se, generando así las condiciones de pervivencia de lo construido en el largo tiempo.

Y esto, trasciende lo escritural. También la historia oral es un desafío al tiempo del olvido. Una constatación empírica de esto nos la dan nuestros pueblos originarios a lo largo y ancho de toda América Latina; aún hoy siguen luchando por el reconocimiento de lo que son desde sus cosmovisiones ancestrales y cosmovivencias que se historizan pero en relación a sus propios modos de comprender la relación con la vida y desde otras claves de pensamiento muy diferentes a las modernas y occidentales.

Así, memoria, historia y olvido significan el modo particular del fluir - siempre complejo - de sujetos históricos que, como lo he señalado, en su narrarse construyen imaginarios 
simbólicos que condicionan, desde las experiencias del presente, una comprensión particular tanto del pasado como del futuro. Es este fluir el que hace que el sujeto histórico sea, por su propia naturaleza creadora de realidades, un sujeto politico.

Sin embargo, la memoria no nos provee de un "formato universal" de organización y registro de los hechos experienciados y vividos. Por el contrario, al dar cuenta de las narrativas historizadas de sujetos concretos, da cuenta de los diferentes modos de comprender la realidad transitada por identidades socio culturales diversas, poniendo en juego una de las actividades psico-cognitivas más complejas y por lo general menos abordadas en los espacios de formación de sujetos, me refiero al pensar categorial y los procesos de interpretación; es decir, a la lectura articulada - en sus distintas dimensiones - de la realidad concreta; lo que implica considerar, en esa lectura compleja, todas las rearticulaciones de memoria posibles que contribuyan a construir y reconstruir presente pasado y futuro ampliando su comprensión - objetivo fundante de la historia - abriéndose constantemente a diferentes posibilidades de futuro. Así, cuando la memoria se amplía en comprensiones más complejas e intentamos descubrir principios organizadores y ordenadores de lo actual y su devenir, la memoria se amplia en historia.

"Es necesario mirara la historia desde el fuego del presente, decía Nicole Loraux. La finalidad de la memoria no es fijar el pasado fotografiándolo. Podemos agregar con Imre Kertész, que la sola visita al pasado puede constituir apenas un archivo descriptivo e inerte, cuando la tarea es más seria: descubrir un principio organizador y ordenador de lo actual. De no lograr esta meta, la visita al pasado será inútil y estéril”. (Puget \& Kaes, 2006, p 10)

Este modo de comprender la memoria y la historia pone en cuestión un "criterio de verdad" fuertemente sostenido por la tradición de pensamiento analítica - positiva, moderna y monocultural - que nos coloca ante una problemática más profunda con respecto a la episteme, es decir con el pensar desde definidas posturas epistémicas, lo que implica unas determinadas formas de ponernos en relación de conocimiento

La historia vista desde la tradición de pensamiento crítico-hermenéutica, es un desafio al logo-centrismo occidental basado en el horror a lo múltiple, como muy bien nos dice JoanCarles Mélich. El desafio es enorme: escuchar a los olvidados, a los ausentes, a los negados - que son las mayorías - por un orden dominante que se ha apropiado de la historia desde una historiografia "científica" y con criterio, vuelvo a decir, de verdad.

"La filosofia occidental ha vivido en el horror a lo múltiple. El logos se ha ido progresivamente afirmando en la medida en que negaba la multiplicidad, la pluralidad, la relatividad. El conocimiento tiene la forma, desde Platón, de un camino hacia la unidad, hacia el orden, la clasificación y el control. Este "horror a lo múltiple" abarca también al Otro". (Mélich, 2001, p 86)

En definitiva la historia es un campo de lucha politica; es un campo de lucha de lectura de realidad y de interpretaciones de esa realidad rearticuada en sentidos y significados que exigen, como lo dice Hugo Zemelman en su magnífica apuesta de epistemología de la conciencia histórica - o del presente potencial -, tener claras las categorías organizadoras de nuestra lectura de la realidad.

En este marco de consideraciones también es importante reflexionar acerca de que, así como la memoria es la construcción simbólica de narraciones que dan cuenta de las experiencias socio culturales experienciadas y vividas por diversas identidades socio 
culturales, también el registro de la memoria adquiere diferentes formas tonos y maneras desafiando la comprensión mayor de los procesos socio culturales de época.

En la línea de estas reflexiones, podría decirse también que las experiencias traumáticas que vivimos los seres humanos en nuestras sociedades de referencia, no siempre son registradas; menos aún si la hitoriografia oficial y oficiosa ha sido escrita por los vencedores y, por ende, sus intereses económicos, culturales - fundamentalmente raciales, religiosos, ideológicos y de clase - y sociales en el marco de políticas coloniales e imperiales. Es con el siglo XX, como muchos historiadores afirman y todos lo sabemos, que Europa y el mundo asumen que la historia no es memoria, pero que sin memoria no hay historia. Los registros del genocidio de Auschwitz, la bomba de Hiroshima o Nagasaki revelan el sentido profundo de esta afirmación: con estas tragedias y su narración se inicia una ruptura determinante con la historiografia "científica" y se abre el espacio a la búsqueda de comprensión de otras dimensiones de lo humano, aún incomprensible, que hacen que el mal y la locura puedan ser política de Estado; pero también se abre el espacio de reconocimiento de los excluidos y su memoria, que aún hoy se está tratando de articular en nuevas corrientes filosóficas e históricas basadas en la ética de la memoria; cabe mencionar a Joan Carles Mélich y Fernando Bárcenas, fecundos intelectuales españoles que a través del proyecto de investigación "La filosofía después del Holocausto" del Instituto de Filosofia del CSIS - Madrid - ha hecho grandes aportes para repensarnos desde otras matrices de pensamiento occidental.

Vale decir que El campo de concentración de Auschwitz-Birkenau fue un complejo formado por diversos campos de concentración y de exterminio construido por el régimen de la Alemania nazi tras la invasión de Polonia de 1939, al principio de la Segunda Guerra Mundial. Situado a unos $43 \mathrm{~km}$ al oeste de Cracovia, fue el mayor centro de exterminio de la historia del nazismo, donde se calcula que fueron enviadas cerca de un millón trescientas mil personas, de las cuales murieron un millón cien mil, la gran mayoría de ellas judias desde su apertura el 20 de mayo de 1940 hasta el 27 de enero de 1945, cuando fue liberado por el ejército soviético. La UNESCO lo declaró Patrimonio de la Humanidad en 1979 como uno de los lugares de mayor simbolismo del Holocausto o Shoah. Por su parte Hiroshima y Nagasaki Como fueron ciudades escenarios del primer bombardeo atómico de la historia, el 6 de agosto de1945, en el final de la Segunda Guerra Mundial, por el bombardero estadounidense Enola Gay, ordenado por el presidente Harry Truman. Este acto bélico, cuyo objetivo fue la rendición rápida e incondicional de Japón a los Estados Unidos, produjo la muerte de alrededor de 120.000 japoneses, en su casi totalidad civiles, dejando un saldo de casi 360.000 heridos, entre los cuales gran cantidad presenta variaciones y mutaciones genéticas debido a la radiación a la cual estuvieron expuestos. Los percances biológicos y anatómicos, por tanto, persisten hasta nuestros dias dentro de la población japonesa.

Narrar el horror en el marco de estas políticas de Estado no es sencillo, porque resulta inverosímil, porque lo relatado no encuentra eco ni registro, ni códigos en la organización simbólica del imaginario social colectivo, no hay referentes de comprensión para absorber lo que se narra. Frente a ello se activan dispositivos que podrian llamarse de evitación; se intenta desconocerlo recurriendo a la desmentida o a diversos mecanismos de defensa.

Escribe Janine Puget (2006, p 25):

"Recordemos lo que le sucedió a Bruno Bettelheim al llegar a Estados Unidos, cuando quiso transmitir su experiencia reciente en el campo de concentración. Nadie deseaba creerlo e incluso se recurrió a ciertos conocimientos psiquiátricos a fin de imponerle un diagnóstico psicopatológico, para así poder desmetir una realidad insoportable." 
Bruno Bettelherim como judio en Austria, desde 1938 hasta 1939, fue prisionero en los campos de concentración de Dachau y de Buchenwald. Llegó a Estados Unidos en 1939, donde se naturalizó ciudadano en 1944. Ejerció como profesor de psicología en la Universidad de Chicago desde 1944 hasta su retiro en 1973. Obtuvo un título en filosofia y fue analizado por el psicoanalista Richard Sterba. Fue profesor de Psicologia de la Educación, director de la Escuela Ortogénica de Chicago (1947-1973) y, desde 1963, profesor de Psiquiatría en la Universidad de Chicago. Pasó gran parte de su vida como director de una sección en la Universidad de Chicago, que servia de hogar para niños emocionalmente perturbados. Escribió importantes aportes acerca de la psicología normal y anormal de los niños. Falleció en 1990

Ante estas y muchas otras experiencias, como las que en América Latina se desataron a partir de los acontecimientos de fines de los años '60 y hasta la fecha en sus múltiples consecuencias políticas económicas y culturales, cabe preguntarse: ¿qué ocurre cuando la memoria colectiva está entrampada en la violencia social y las experiencias traumáticas? ¿Cómo operamos frente a estas razones de cierta locura social que atraviesa la vida cotidiana en términos subjetivos y colectivos de pueblos enteros con bases políticas y efectos psicosociales que aún no podemos desencriptar?

Desde la Escuela de las Américas en Panamá y su acción en las dictaduras de los años '70 en el Cono Sur - con su tecnología de la tortura, sobre todo en Argentina - y Centro América, pero también en las dictablandas del escritor mexicano Carlos Fuentes y en los actuales programas gubernamentales de lo que llamo dicta-democracias en algunos de nuestros países - con honrosas excepciones de los integrados en la UNASUR - mucho tenemos para contar acerca de la violencia de Estado y sus horrores; cargando, como bien dice Hugo Zemelman, con almas rotas y haciendo con ellas memoria e historia - como podemos -.

El "Instituto del Hemisferio Occidental para la Cooperación en Seguridad"- en inglés: Western Hemisphere Institute for Security Cooperation -, conocido también por su nombre anterior, "Escuela de las Américas", es una organización para instrucción militar del Ejército de los Estados Unidos situada en Fort Benning, en la localidad estadounidense de Columbus, Georgia. La escuela estuvo situada desde 1946 a 1984 en la Zona del Canal de Panamá, donde actualmente -y desde el año 2000- funciona el hotel Meliá Panamá Canal. Se graduaron más de 60.000 militares y policias de hasta 23 países de América Latina, algunos de ellos de especial relevancia por sus crimenes contra la humanidad como los generales Leopoldo Fortunato Galtieri, de Argentina; Manuel Antonio Noriega, Panamá; y Manuel Contreras, de Chile. En este lugar se adiestró y entrenó en métodos de tortura, asesinato y represión a miles de represores de toda Latinoamérica. Su actividad continúa hasta el dia de hoy.

Para profundizar en este punto, quisiera tomar algunas reflexiones que considero de valor y sugerentes en la comprensión histórica y política de estas experiencias traumáticas retomadas de historiadora argentina Beatriz Gentile (Entre muchos otros textos quisiera mencionar aquí "Cadáveres y votos. Claves para pensar la violencia institucional". Edit. Autores de Argentina. 2013 y su presentación en los "X Octubres Latinoamericanos de IPECAL" Oaxaca, México) y que me llevan a repensar las posibilidades de repensar las maneras de hacer memorias compartidas que podrian entrecruzar nuestras prácticas políticas y que podría comprenderse de la siguiente manera:

- Memorias sentipensadas desde la externalidad, organizadas en "objetos" que dan cuenta de lo ocurrido a-hsitoricamente, ubicando lo sucedido en un "pasado que ya pasó". "Fuera de un contexto histórico que las explique... En este "congelamiento" del pasado, las experiencias traumáticas sufren un proceso de des-historización al quitarles el 
entramado de relaciones y contradicciones que hicieron posible que sucedieran." (Gentile, "El recuerdo del "Mal": Historizar la memoria", 2015)

Estas memorias se traducen en mecanismos que, en mi opinión, son respuesta de época a los "contextos de producción de violencia-terror, de derrumbe de la legalidad, de fraccionamientos destructivos, de pérdida de la ética fundamental para el mantenimiento de relaciones sociales" (Puget \& Kaes, 2006, p 37) nacidos con el S XX y que aún nos transitan como locura social, llegando incluso a convertirse en bases para politicas públicas. En esta perspectiva podrian considerarse unas formas de producción material tales como:

- Memoria estetizante: centrada en la descripción de lo sucedido en situaciones muchas veces de horror - campos de concentración, tortura, etc. - de manera expositiva; generando, incluso, "muestras" del horror - en diferentes estilos artísticos - donde se modula de alguna manera un pasado que ya pasó.

Esto podemos verlo en exposiciones fotográficas, museos, mausoleos, etc. que "descarnan" hechos insoportables que ya sucedieron y que se supone, no volverán a pasar: al exponer las experiencias traumáticas en objetos estéticos concretos como obras de arte, esculturas, performatividades y arquitectura ad hoc pareciera que se pretende recordar lo que ocurrió para que no vuelva a ocurrir, propiciando así un proceso de "olvido sutil" del impacto que esto causó en los sujetos concretos, sus subjetividades y las redes que se activaron social e intersubjetivamente y por lo tanto de la relevancia del suceso; y, como consecuencia, del suceso mismo.

Cabe aclarar que en ningún modo estas reflexiones en relación a la memoria estetizante niegan el valor de estas apuestas estéticas que nos recuerdan lo que no deseamos vuelva a suceder. En todo caso es sustantivo el llamado a no confundir "... lo que sería un intento deliberado de burocratizar el dolor, de esconderlo "debajo de la alfombra", un acto superficial de memoria que puede tener cualquier intención menos la de recuperarla; es riesgoso suponer que "toda" puesta estética es manipulada. Indudablemente puede ser, a la vez, un trabajo valiosísimo de las sociedades para elaborar aquello que no tiene nombre, ni lo va a tener. Ese horror. Museos, estatuas, eventos, libros, películas, placas. Todos son actos que tienen un trasfondo simbólico; $y$, más que ocultar, lo que hacen es hacer presente constantemente el dolor y lo alivian tratando de avanzar minimamente con un significado sobre eso que en uno, se vuelve catárquico. Creo importante hacer claramente esta diferencia" (Ahumada, 2014)

Es en este marco de consideraciones que creo que es necesario insistir en que estas muestras estéticas tienen que ir acompañadas de otros procesos fundamentalmente formativos y de conciencia histórica, de lo contrario, podrian contribuir a construir olvido por impacto, o fijar, como se dijera, el horror en un "pasado que ya pasó".

Son muchos los movimientos que podrian reconocerse en américa Latina. Un ejemplo de estos movimientos que se organizan para soportar lo vivido y su consecuencias como pueden ser: la Asociación de Derechos Humanos H.I.J.O.S Sus objetivos son la lucha contra la impunidad, la reconstrucción fidedigna de la Historia, la restitución de la identidad de los hermanos y familiares secuestrados y apropiados, así como la reivindicación de la lucha de sus padres y sus compañeros. Como colofón, la cárcel efectiva y perpetua para todos los responsables de crimenes de lesa humanidad de la última dictadura cívico-militar argentina, sus cómplices, instigadores y beneficiarios. Hoy tienen seguidores y actuación en casi toda américa Latina. Otra de las Asociaciones 
que podría mencionarse en este sentido es la de las Madres de Soacha. Soacha es una ciudad colombiana donde un grupo de madres se han unido para reclamar justicia por la muerte de sus hijos. En 2008, el ejército de Colombia mató a más de una docena de hombres jóvenes y mintió al presentar la mayoría de los cadáveres como los de "guerrilleros muertos en combate", lo que actualmente se llaman "falsos positivos". Desde entonces, sus madres han trabajado incansablemente para conseguir justicia. Y no ha sido fácil: en su campaña, han sido amenazadas, hostigadas y sometidas a vigilancia con el fin de silenciarlas. En mayo de 2010, miles de personas enviaron rosas y mensajes de solidaridad para las Madres de Soacha. Ahora saben que cuentan con el apoyo de miles de personas solidarias en todo el mundo.

- Memoria moralizante esta memoria es fundamentalmente "discursiva", llena de afirmaciones que hacen a la "adjetivación" de lo ocurrido centrando la atención en víctimas y victimarios, en "buenos" y "malos" -o en la teoría de los dos demoniossancionando moralmente a los "malos" y volviéndolos chivos expiatorios de situaciones que "no podrán seguir ocurriendo". Es este otro modo de descontextualizar los sucesos, se señala culpables y se pontifica víctimas o salvadores sin ahondar en por qué sucedió lo que sucedió; de este modo los hecho dejan de ser sintomas socio culturales, politicos y económicos para pasa a ser acciones de unos pocos inadaptados que la sociedad debe inhibir en su accionar para no permitir que vuelva a suceder lo sucedido. Es un discurso sin responsables -como en toda relación víctima/victimario- puesto que la responsabilidad se diluye en claves de despersonalización y culpas "del otro" o de las circunstancias, siendo "las circunstancias" una generalización: la sociedad, el mal, el "complot", el maltrato injusto contra alguien. Resulta imposible pensar en responsabilidades concretas, argumentadas con sentido, así como en atribuciones en la resolución del problema.

Esto permite que, en el campo de lo social y político, se victimizen quienes por mandato son autoridades y/o representantes del orden totalitario pero también democrático, quienes son, a la vez victimarios (Desinformemonos, 2014)

Este suele ser un recurso muy socorrido en el discurso político y aún más por quienes gobiernan o gobernaron provocando acciones propias de lo que hoy llamamos terror de Estado.

- Memorias sentipensadas desde el presente: resignificando el pasado en el devenir de la realidad concreta. En esta perspectiva el pasado no pasa, al pasado se lo re-visita para preguntarle para comprender con mayor profundidad y amplitud lo que nos ocurre mientras está ocurriendo aquí y ahora, y desde allí imaginar futuros posibles.

En esta postura lo sucedido no es sólo recordar hechos "objetivos" sino que además, y fundamentalmente, se reconoce el accionar de los sujetos históricos y las sociedades, leyendo críticamente el momento histórico, entendiendo que el pasado no pasa, menos aún las experiencias sociales traumáticas como las que se dan en los procesos de terror de Estado, puesto que el terror de estado genera una sensación tal de incertidumbre e impotencia tal que altera enormemente lazos imprescindibles de pertenencia, confianza y arraigo llegando a desvanecerlos, con la consecuente modificación de la estructura subjetiva, intersubjetiva y por ende socio cultural que esto implica. Ya lo decía Marcuse en su magnífica obra "Eros y civilización" (Marcuse, 1983) y más recientemente Norbert Lechner (2002, p 16) afirma "... son los años de plomo bajo la dictadura de Pinochet, los que enseñan cuán imbricadas están experiencias subjetivas y orden politico. Desde entonces, creo yo, mi reflexión gira en torno a la subjetividad social. Hace años y de manera cada vez más explícita, me dedico a explorar la carga subjetiva de la política" 
Desde esta perspectiva, el pasado es siempre pasado cercano porque tiene vigencia en el sentirpensar de los sujetos históricos que configuramos las diferentes identidades socio-culturales que transitamos; aunque sus hechos y acontecimientos hayan sucedido mucho tiempo atrás, como sucede con los pueblos originarios.

El pasado es cercano en tanto se presentifica constantemente -por sus efectos- en nuestra vida cotidiana, en nuestras subjetividades y en nuestro transitar como sujetos sociales que viven en relación.

Podríamos señalar dos modos de hacer esta memoria que se enmarca en la tradición de pensamiento crítico hermenéutico:

- Memoria histórica. Se activa en la lectura critica del presente; lo que implica el uso de categorias articuladoras fundantes en el pensamiento complejo e histórico como son totalidad y dialéctica. Es, desde esta lectura crítica y compleja del presente, que el pasado comienza a tejerse en renovados sentidos y significados que agudizan la comprensión de los fenómenos sociales que ocurren en las coordenadas del presente historizado, desde sus hechos y acontecimiento. Y es desde esta comprensión desde donde es posible pensar -con imaginación radical, diría Cornlius Castoriadis-opciones de futuro que nos lleven a trascender la repetición de lo dado.

Esta postura ha sido desarrollada en América Latina -tanto teórica como metodológicamenteen la obra y el pensamiento zemelmaniano. (Zemelman M. , 2011)

- Memoria traumática. Así como la memoria es una organización de lo experienciado y vivido en la narración de los sujetos, la memoria traumática se caracteriza en la paradoja de ser una organización de hechos desorganizada, diría rasgada, rota, que se retiene en un campo emocional latente de dolor y horror; las palabras conocidas no alcanzan para explicar lo no explicable porque no hay registro en lo simbólico de lo que ocurre en lo real, diría Lacan.

La memoria se va registrando asi en narraciones descriptivas de las experiencias y hechos frente a lo increíble, fragmentándose y desarticulándose de las redes de relaciones del contexto que las produjo. Es una fijación que intenta, en la repetición de la experiencia, metabolizar lo indescifrable a la vez que exorcizar lo indecible.

Es esta una construcción memoriosa de lo ocurrido que recurre siempre a lo real sin poder ser simbolizado y, por lo tanto, comprendido y organizado. Es una memoria que entrampa en el campo emocional del horror de un pasado cercano que no termina de pasar porque no se logra procesar en la dinámica de subjetivar y objetivar en conocimiento y compresión. No es una cuestión "temporal", es una cuestión traumática que, como tal, marca, fija el hecho, paralizando los posibles campos de comprensión y producción de conocimiento. Las masacres humanas retornan sin poder ser nombradas como hechos y/o acontecimientos sintomáticos de locura social y/o terror de Estado. Se convierten así en una memoria impotente y tanática. El presente evoca constantemente la experiencia traumática sin poder trascender comprensivamente ese campo emocional.

Quisiera hacer aquí dos señalamientos que considero necesario aclarar:

El primero tiene que ver con la comprensión epistémica de estas formas de organización de la memoria. Y digo "formas de organización" y en ningún modo "clasificación" cosificada. Estas formas tienen movimiento y especificidad histórica; y, en este sentido, son "alertas" 
de lectura crítica en tanto construcciones dicientes de intereses socio-políticos pero también de exigencias de razonamiento para cada uno de nosotros, sujetos históricos y comprometidos con memorias de sentido. Ése es un trabajo subjetivo e intersubjetivo que hace a las comunidades de buen sentido, como bien decía Antonio Gramsci, y esto depende más de la voluntad de conocer que de las políticas de Estado que van más allá de nuestro propio mirar.

El segundo tiene que ver con el concepto de subjetividad social que asumo y al que hago múltiples referencia en estas reflexiones que comparto y dono.

Si bien “...la subjetividad apunta a la singularidad y es algo inasible, inaprensible, siempre en fuga y por eso mismo imposible de determinar... hay fenómenos que tienden a modificar, a formar, a manipular subjetividades y en ese sentido articulan-como condicionantes socio culturale - tendencias que afectan a la configuración de subjetividades, desde sus historias y particularidades, que dan vida a lo social pero esto no puede ser, en ningún modo, un "corpus", una estandarización de la subjetividad-mucho menos homogéne-que conforme sociedad" (Ahumada, 2014)

Es desde este marco de consideraciones que asumo el concepto de subjetividad social, haciendo énfasis - desde una argumentación que expresa un modo de comprender los aspectos trabajados - en las condiciones que afectan a las subjetividades generando imaginarios sociales amenazantes que actúan con fuerza feroz en el inconsciente colectivo, impactando formas de sentir, pensar y hacer; más aún cuando de pedagogías del terror se trata.

Es en esta perspectiva que vengo argumentando, podríamos preguntarnos:

¿Qué ocurre cuando este narrar-se de los sujetos históricos de una sociedad queda fijada en la narración de las experiencias traumáticas que marcan la vida de los sujetos sociales que la habitan? ¿Cómo pueden sujetos configurados en la violencia pensarse como sujetos de paz o en procesos de paz?

\section{Memoria traumática. Impotencia alienante y práctica política en América Latina.}

Podría decirse que América Latina es "parida", en 1492, por la barbarie lo cual puede verse en las matanzas y la crueldad para con los pueblos originarios y la esclavitud tanto de indígenas como del pueblo africano, descriptas en múltiples crónicas de la época.

Barbarie que ha dejado marcas indelebles en la memoria y la historia tanto en nuestros cuerpos como en nuestras creencias y ha moldeado de una manera u otra nuestros valores sociales y culturales.

Religión, coloniaje y economía extractivista del capitalismo de acumulación fueron las claves de las negociaciones globalizadoras e imperialistas de la época-siglo XV-entre los Reyes de Castillas y el Papa Alejandro VI. Y resulta de suma importancia mantener estas tres claves claras y presentes, ya que se configurarán en el eje articulador que atravesará a América Latina - aún hasta hoy-, en lo que Aníbal Quijano nombra como colonialidad del poder. (Quijano, 2000, p 246)

Más tarde, con los procesos de organización nacional, las claves siguen siendo las mismas: religión, coloniaje y economía extractivista -ahora del capitalismo de producción- pero articuladas por un poderoso eje colonizante "moderno" que orienta y organiza lo político, lo económico y lo social de este largo período, penetrando de manera determinante, 
sistematizada e institucional -a través del sistema educativo-: me refiero al orden de lo cultural. Una apuesta epistémica positivista -moderna e iluminista- que instaura la muletilla civilización y barbarie configurando códigos simbólicos y claves de pensamiento donde el entorno es externo al sujeto: lógicas de razonamiento que se organizan desde la externalidad, binaria, lineal y causal, clasificatoria y jerárquica ; entronizando una clara des-subjetivación de la reflexión social reducida a "objetos" medibles, evaluables y... contables"... una manera de legitimar el saqueo constante a las "venas abiertas" (Galeano, 1971) de América Latina bajo el imperio de la "verdad" y la racionalidad instrumental.

Así, esta América Latina cobriza y acrisolada, va configurándose en una subjetividad social que se estructura en la emergencia de una relación que la define hasta hoy; la tanática relación que se establece entre victima y victimario; entre colonizador y colonizado o entre amo y esclavo. Relación circular y recurrente que se sustenta en la culpa y la alienación.

Pero es a partir de fines de los '60 en que el terror de Estado asume la limpieza, ya no sólo étnica, racial y/o de clase sino ideológica, herencia fiel del macarthismo instalado en Estados Unidos en el marco de la guerra fría. Limpiezas que se asumen como politica de Estado; y se actúa sobre una clara estrategia que toma como base tres claves de acción del terror "... crimen politico, violencia institucional e impunidad... Tres vértices de un triángulo en el que cada uno de ellos comparte relaciones de reciprocidad con el otro..." para lo cual usa, necesariamente, la fuerza de gobiernos dictatoriales.

Vale la pena aclarar qué; el macarthismo es un término que se utiliza en referencia a acusaciones - generalmente oportunistas, pero siempre falsas - de deslealtad, subversión o traición a la patria sin el debido respeto a un proceso legal justo donde se respeten los derechos del acusado. Se origina en un episodio de la historia de Estados Unidos que se desarrolló entre 1950 y 1956 durante el cual el senador Joseph McCarthy (1908-1957) desencadenó un extendido proceso de delaciones, acusaciones infundadas, denuncias, interrogatorios, procesos irregulares y listas negras contra personas sospechosas de ser comunistas. Los sectores que se opusieron a los métodos irregulares e indiscriminados de McCarthy denunciaron el proceso como una "caza de brujas" y llevó al destacado dramaturgo Arthur Miller a escribir su famosa obra Las brujas de Salem -1953. Por extensión, el término se aplica a veces de forma genérica para aquellas situaciones donde se acusa a un gobierno de perseguir a los oponentes políticos o no respetar los derechos civiles en nombre de la seguridad nacional.

Para muestra de esta acción política intencionada, basta leer las declaraciones de Ramón Díaz Bessone, integrante de la dictadura Argentina, nada original en la época puesto que es una afirmación que se repite en los dictadores de toda América Latina “...teníamos que exterminar a la subversión y esto no se podia hacer legalmente, porque luego lo sectores civiles no sólo amnistiaban a los subversivos, sino que si se les hubiese exterminado públicamente hasta el Papa habría protestado, como sucedió en el caso chileno..." El aniquilamiento del considerado enemigo fue un mandato generalizado en las fuerzas militares de América Latina como bien lo han demostrado también los reconocidos Kaibiles, soldados de élite del Ejército de Guatemala, preparados para llevar a cabo operaciones especiales y de inteligencia que actúa en otros países y desde 1975 en Guatemala (Rizzi, 2005)

Desde estos tiempos, los sujetos sociales e históricos que habitamos América Latina, hemos perdido la inocencia. Ahora sabemos que los demonios se pueden soltar, que la locura puede ocupar al Estado que tiene como función protegernos y que la crueldad ha adquirido un rol definido en la sociedad, el de la profesionalidad en la tortura ¿puede ser esto posible? Aún, muchos, nos los preguntamos... 
Como también nos preguntamos “... ¿Cómo procesó cada sociedad la falta de castigo de asesinatos en masa, violaciones, robos de niños y tortura? (Gentile, Cadáveres y votos. Claves para pensar la violencia institucional, 2013) ¿Realmente se han naturalizado en la sociedad en su conjunto estas prácticas? ¿Cuáles son y han sido los mecanismos psíquicos para convivir con esta historia de horror que ha tocado a la mayoria de familias latinoamericanas marcadas por el desplazamiento, los duelos sin cuerpo -por desapariciones forzadas- la objetivación de la crueldad en narraciones documentadas y expuestas públicamente? ¿Cómo se elabora la muerte por asesinatos brutales por tortura y/o formas modelizadas de crueldad psicológica o físicas innecesarias? ¿Qué ocurre con los profesionales de la muerte y la tortura cuando se abren los períodos democráticos -concertados, negociados o impuestos- como parte de nuevos procesos de intervención del orden dominante.

Sin lugar a dudas, estas formas de dictadura agudizaron, cada vez más, la ruptura del tejido social que se profundiza en el largo tiempo por un miedo larvado que queda grabado en el ADN de los sujetos sociales y sus subjetividades, surcados por las marcas que dejan estos períodos de terror de Estado político y la ruptura de lazos; sustrato ideal para las nuevas formas de dictaduras: económica -con un Estado que administra las exigencias de agencias internacionales en la constante modificación tanto de leyes fiscales y reordenamiento de las leyes de mercado internacionales y regionales-; simbólica-dada fundamentalmente por una semántica del orden dominante viabilizada por los medios de comunicación masiva -; y de la in-seguridad, basada en la creación del terrorismo internacional y la delincuencia organizada.

En nuestro contexto latinoamericano, esta contante reorganización del orden establecido y el capitalismo totalitario se agudiza visiblemente en países como Colombia, El Salvador, Guatemala y ahora México, entre otros, atravesados por la delincuencia organizada, que recupera a muchos de los profesionales de la muerte y la tortura "desocupados" con la llegada de los procesos democráticos o pseudo-democráticos que se fueron recomponiendo en el continente, en un marco muy diferente de comportamiento social y politico.

Así, sobre el terror de Estado y sus efectos soterrados en el conjunto de la población, emergen el terror delincuencial propio de la delincuencia organizada-vinculada fundamentalmente al narcotráfico pero también a los grupos paramilitares- y también de la corrupción como delincuencia infiltrada en la vida cotidiana por el germen de la súper o sobre vivencia y la pérdida de los límites básicos de acuerdos sociales basados en el cuidado de la vida misma, invadiendo todos los ámbitos de la cotidianeidad como virus social, adquiriendo proporciones inimaginables en un constante trabajo de hormiga de erosión de lo común en procesos cada vez más legitimados de privatización de lo público que invade hasta las prácticas más básicas de convivencia en las relaciones institucionales tanto gubernamentales como no gubernamentales.

¿Qué efecto causa esto en el día a día de los sujetos concretos y su subjetividad? ¿Qué tipo de relaciones sociales se generan?

Se instalan conceptos que reestructuran las redes de relaciones, prácticas y representaciones reordenando formas de vinculación intersubjetiva y por ende social; conceptos que configuran una episteme particular dada en claves de pensamiento, y por ende de acción de vida cotidiana, de la época: miedo, inseguridad y precarización, configuran un trípode tanto en lo simbólico como en lo material- donde se asienta el sin-sentido o el "avance de la insignificancia" como muy bien auguraba Cornelius Catoriadis (Castoriadis, 1997) ; o bien en la llamada "crisis de representación" para dar cuenta de lo que nos ocurre. 
¿Cómo se vive en estos espacios articulados alrededor del miedo que fluye entre la impotencia y la devastación transitada por una memoria traumática y por una economía capitalista totalitaria que precariza cada vez más la vida de los ciudadanos que sostienen con su esfuerzo a las naciones del continente? ¿Cómo se vive en este miedo que capilariza las relaciones de la subjetividad social?

Indudablemente mucho hay por escribir en este sentido; más aún por revisar de cuál es el efecto psicosocial de estas prácticas de terror de Estado y su herencia en el terror delincuencial micro y macro, pero quisiera aquí destacar alguno de los aspectos que considero fundamentales en la articulación del tejido social actual y su efecto en los mecanismos psíquicos de organización de la realidad en la subjetividad social de América Latina en general y de algunos países en particular como Colombia, Chile y actualmente México.

Me refiero a la constitución de subjetividades sociales estructuradas -y entrampadas- en y desde:

- Memorias traumáticas organizadas alrededor de experiencias -siempre cercanas y recurrentes- de horror no elaborado; centrada en la víctima más que en la lectura comprensiva de por qué ocurrió lo que ocurrió y el efecto psicosocial y cultural de eso ocurrido que sigue ocurriendo y que deja como consecuencia una imposibilidad cada vez más profunda de comprensión del presente y por ende del pasado con el consiguiente efecto en el futuro.

- Alienación social como mecanismo de defensa ante lo que no se puede olvidar -porque pervive y se presentifica constantemente desde el inconsciente colectivo- pero también ante las actuales políticas de Estado basados en el control de lo que es modo de pensar -como claves de época- pero también de vivir miedo, inseguridad y precarización; claves y prácticas políticas y sociales que le dan sentido y contenido a una biopolitica del Estado (Bauman \& Dessal, 2014)

La alienación implica el alejamiento de sí para enajenarse en otro -sujeto, causa, ideologíaque el sujeto alienado actúa como propio; de alguna manera se produce una "desconexión", un "anestesiamiento" del propio deseo para operar desde el deseo que aliena.

Señala Piera Aulagnier (1998): “...La alienación se propone reducir al mínimo el conflicto y el sufrimiento psíquico que resulta para el yo..." y puede darse en situaciones diferentes: porque el sujeto esté "entrampado" en un sistema social o de dominación o bien por una patología identificatoria o de idealización del propio sujeto en su proceso de configuración subjetiva.

En el caso que nos interesa,

“... el sujeto puede hallarse preso en un sistema social y en un sistema de poder que le impide pensar libremente (o simplemente pensar) ese sistema... Esta interdicción establecida por el poder, que amenaza de muerte a esos pensamientos, a más o menos corto plazo será interiorizada por el sujeto no solamente por un reflejo de defensa vital, sino porque pensarse "esclavo", puro instrumento al servicio del otro, objeto carente de todo derecho de palabra y de pensamiento, sería efectivamente para el yo la fuente de sufrimiento... "(Aulagnier, 1998)

Nuestras sociedades están, de algún modo, alienadas por la triada miedo/inseguridad/ precarización, lo que impacta subjetivamente en la capacidad de pensar, de imaginar y 
de autonomización. Así, la subjetividad -y por ende las relaciones intersubjetivas- se va impregnando y saturando de incertidumbre, ambigüedad y desconfianza; el otro se vuelve amenazante y el sujeto se zoologiza en el cada vez menor movimiento del sentir, del pensar y del hacer, transformándose en lo que Zemelman ha denominado sujeto mínimo; productor, como consecuencia, de sociedades minimizadas y amenazadas que navegan en el fangoso pantano de la ambigüedad como forma de relación.

Memoria traumática y alienación social derraman, intencionalmente, un sentimiento común: impotencia erótica y vulnerabilización de los lazos sociales.

\section{La formación de sujetos, desafio de estos y todos los tiempos.}

¿Qué es posible hacer ante lo expuesto? ¿Sólo es posible hacer una "lectura" crítica de la realidad? ¿Cómo actuar frente a una sistemática destrucción de los lazos de humanidad que configuran sociedad y la alienación tanática de vida cotidiana en nuestros países? ¿Cómo movilizar dispositivos que desactiven estos procesos de desconfianza, ambigüedad, minimización y zoologización socio cultural en la vida cotidiana de nuestros espacios vitales? ¿Cómo luchar contra las políticas de olvido?

Desde IPECAL, como proyecto ético político e intelectual, estamos convencidos que uno de los medios más eficaces para trasformar este estado de cosa son los procesos de formación de sujeto, como práctica política.

Y digo formación, porque el sólo concepto remite a una comprensión más humanizada de un proceso que, entendemos, se mueve en una de las dimensiones más complejas del hacer mundo de la vida; dimensión por la cual fluimos configurándonos y configuramos, a su vez, realidades desde nuestras subjetividades -y por ende intersubjetivamente-, lo que nos convierte en sujetos sociales e históricos, me refiero a la dimensión de la cultura.

Indudablemente no me estoy refiriendo a "reformar" planes y programas de estudio, ya sabemos que esto no ha aportado gran cosa ni a nuestros estudiantes ni a nuestras sociedades; y esto a pesar de las muchas reformas que nuestros sistemas educativos han "sufrido" y de los actuales sistemas de "certificación de calidad" de las instituciones educativas. Por el contrario, las politicas públicas de Educación en América Latina -en todos los niveles de enseñanza- después del consenso de Washington y de los programas basados en competencia - proyecto Tuning- traídos de una Europa hoy sumida en una enorme crisis de todo orden, ha sido de gran empobrecimiento de saberes pero, fundamentalmente, del pensamiento como disposición fundamental para hacer frente a las vicisitudes que traen estos tiempos de grandes cambios como los que vivimos después de la segunda revolución de la ciencia y la técnica de mediados del SXX.

Me refiero más bien a procesos de formación que anclen en un cambio epistémico -y por ende en modos de pensar y producir conocimiento- que nos permita recuperar al sujeto alienado por la locura social pero sobre todo con herramientas que nos posibiliten operar en un mundo gobernado por la inseguridad y la incerteza (Bauman \& Dessal, 2014) ; una pedagogia de la dignidad del estar siendo en una tierras donde la dignidad está siendo contantemente puesta en riesgo de muerte. Una pedagogía de la hospitalidad y la donación, una pedagogía que haga de la memoria y la historia la construcción de la identidad comunitaria y la posibilidad de pensar históricamente por sobre la erudición a-histórica y el sin sentido; una formación centrada en la construcción de proyectos de vida sentipensados por sobre la mercantilización y la competencia sin salida que instrumentaliza cuerpos y vidas; una formación que incorpore el mal y el totalitarismo como experiencias humanas 
para comprender y comprendernos en nuestros presentes y exorcizar futuros de horror.

Una formación que se centre en el pensar históricamente más que informar modernamente.

Como bien dicen Carles y Bársena, (2000):

“... sin una organización burocrática extendida a gran escala en sujetos incapaces de pensar por si mismo y sin una tecnología desarrollada al margen de la conciencia moralmente formada, no hubiese sido posible el asesinato en masa."

Es en este sentido, y con el aporte categorial de algunas de las perspectivas teóricas y metodológicas sustantivas en nuestros procesos formativos tales como la Epistemologia de la Conciencia Histórica o del Presente Potencial de Hugo Zemelman (1992); la Pedagogía de la potencia; las Pedagogias Latinoamericanas de Carla Wainsztok; la Educación Como Acontecimiento Etico de Joan Carles Mélich (2000) y la Didáctica del Sentido o Noparametral (Quintar, La enseñanza como un puente a la vida, 1998) (Quintar, Didática problematizadora e integradora, 1996), es que propiciamos procesos de formación de sujetos que tienen como base de pensamiento y acción:

- La generación de condiciones para pensar históricamente, activando dinámicas de lectura crítica del presente.

- La construcción de conocimiento histórico, lo que implica facilitar condiciones de formación enactivo; es decir, en constante ampliación de conciencia y de conciencia histórica, ampliando el ángulo de mirada de lo que se muestra para:

- Repensar el presente en la complejidad de sus múltiples relaciones para así potenciar horizontes de futuro posible

- $\quad$ Organizar el pensamiento desde el pensar categorial en sus dimensiones psicocognitivas, lo que implica la articulación de las múltiples relaciones que conforman a la realidad histórica; la totalidad como principio rector del conocimiento histórico y complejo; la complejidad creciente que rompe con la premisa positiva de lo gradual que va de lo particular a lo general.

- Desplegar una radical imaginación que permita romper parámetros instituidos y hacer de la pasión instituyente un modo de ser y vivir en nuestros tiempos

- Potenciar al sujeto provocando: deseo de saber y pensamiento crítico e histórico, lo que implica ir más allá del ser "informado" acerca de la actualidad de "objetos" teóricos -en boga o clásicos-, lo que suele suceder con el "pensamiento ilustrado" y des-historizado.

- Activar al sujeto en su subjetividad y en espacio de vida comunitaria; vida que exige prácticas, relaciones y representaciones del otro y de lo social basado en:

- La impecabilidad de la palabra como alternativa para desvanecer la ambigüedad y la desconfianza en vínculos intersubjetivos e institucionales.

- La congruencia entre lo que se siente, piensa y hace.

- La responsabilidad de sí en relación al otro; es decir: 
- $\quad$ salir de las relaciones recurrentes víctima/victimario que culpan y se colocan constantemente desde la externalidad corrigiendo y juzgando más que buscando comprender

- $\quad$ construir acuerdos desde la diferencia como proceso de construcción de libertad; puesto que la libertad es la capacidad de elegir y hacerse cargo de lo que se elige

Propiciar modos de diálogo y comunicacionales de apertura a la relación asumiendo la diferencia como posibilidad y no como amenaza

Promover procesos de cada vez mayor autonomización asumiendo que la vida en sociedad es de naturaleza heterónoma.

Considerar como condición de conocimiento y forma de construir conciencia histórica a la memoria e historia, lo que implica recuperar al pensamiento y a los pensadores latinoamericanos como sustrato de nuestro estar siendo y la propia historia como texto necesario para comprendernos a nosotros mismos y las coordenadas de época donde actuamos, asumiendo que somos lo que recordamos

Comprendemos, desde estos criterios de acción formativa que, recuperar el sentido epistémico de la memoria y la historia implica asumir quienes somos como seres esperanzados y creativos pero también como seres embargados por lo irracional y la locura social, y asumirlo hará que comprendamos más y mejor nuestro presente, para realmente salir de memorias traumáticas que nos paralizan para ser sujetos potenciadores de mejores mañanas, con almas menos rotas y ambiguas, cada vez más nosotros mismos y en la valentía de estar en relación humana y de conocimiento, como sujetos y como sociedades con capacidad de construir cada vez más y mejores sentidos de vida subjetiva y comunitaria para merecernos este enorme don de ser humanos y ser humanos latinoamericanos.

Nosotros creemos fuertemente que “... es posible pensar la educación como acompañamiento, hospitalidad y recibimiento del otro en su radical alteridad; y que contra la "horrible novedad" del totalitarismo, es un deber pensar la educación como natalidad y creación de novedad... es decir, como acontecimiento ético"

“...La historia es lo historizable, en tanto ampliación de la subjetividad...” y es aquí nuestro gran desafio, puesto que "...el poder dominante necesita, cada vez más, de almas rotas así como las almas rotas de la subordinación al orden dominante..." Hugo Zemelman 


\section{Referencias Bibliográficas}

Ahumada, D. (2014). Diálogos.Psicoanálisis y memoria. México: Ipecal.

Aulagnier, P. (1998). Los destinos del placer. Alienación, amor, pasión. México: Paidós.

Bárcena, F., \& Melich, J. (2000). La educación como acontecimiento ético. Natalidad, narración y hospitalidad. México: Paidós.

Bauman, Z., \& Dessal, G. (2014). El retorno del péndulo. Sobre el psicoanálisis y el futiro del mundo liquido. México: Fondo de Cultura Economica.

Castoriadis, C. (1997). El avance de la insignificancia. México: Eudeba.

Desinformemonos. (2014). Desinformemonos. Periodismo desde Abajo. Obtenido de desinformemonos.org.mx: http://desinformemonos.org. $\mathrm{mx} /$ ?s=ayotzinapa

Dilthey, W. (1983-1986). Crítica de la razón histórica. Barcelona: Península.

Galeano, E. (1971). Las venas abiertas de América Latina. Mexico: Siglo XXI.

Gentile, B. (2013). Cadáveres y votos. Claves para pensar la violencia institucional. Buenos Aires: Editorial Autores de Argentina.

Gentile, B. (2015). "El recuerdo del "Mal": Historizar la memoria". El Agora USB, 15(2).

Jauretche, A. (1982). La colonización pedagógica y otros ensayos. Argentina: Centro Editor de América Latina.

Lechner, N. (2002). Las sombras del mañana. La dimensión subjetiva de la política. Buenos Aires: Editores Independientes.

Marcuse, H. (1983). Eros y civilización. Barcelona: Planeta.

Mélich, J. (2004). La ausencia del testimonio. Ética y pedagogía en los relatos del holocausto. Eduga: revista galega do ensino(42), 199-201.

Puget, J., \& Kaes, R. (2006). Violencia de estado y psicoanálisis. Mexico: Lumen.

Quijano, A. (2000). Colonialidad del poder, eurocentrismo y América Latina. En E. Lander, La colonialidad del saber: eurocentrismo y ciencias sociales. Perspectivas Latinoamericanas. Buenos Aires: Clacso.

Quintar, E. (1996). Didática problematizadora e integradora. México: UNAM.

Quintar, E. (1998). La enseñanza como un puente a la vida. Buenos Aires: Colección Conversaciones didácticas.

Rizzi, A. (24 de Julio de 2005). El genocisio impune de Guatemala. Obtenido de elpais.com: http://elpais.com/diario/2005/07/24/domingo/1122177157_850215.html

Romano, V. (2005). Intoxicación Linguistica. El uso perverso de la lengua. Caracas: El perro y la Rana. 
Tasso, P. (2014). La historiografía oficial de 1968. Obtenido de http://posgradocsh.azc. uam.mx/: http://posgradocsh.azc.uam.mx/egresados/079_TassoP_Historiografia_oficial_1968.pdf

Zemelman, H. (1992). Los horizontes de la razón I. Dialéctica y apropiación del presente. Mexico: Anthropos.

Zemelman, M. (2011). Horizontes de la razón III. El orden del movimiento. Anthropos. 
